\title{
Transitar a la sostenibilidad
}

Brigitte Baptiste

La estrategia verde o Green Deal con el que la Unión Europea plantea la recuperación pos-COVID-19 “...es, ante todo, una propuesta económica”. Palabras de su embajadora en Colombia, Patricia Llombart, para enfatizar el carácter práctico de las medidas que ya se comienzan a tomar en el viejo continente para reactivar la producción sin volver a superar los límites planetarios, o incluso, para retraer los efectos destructivos de la transformación del territorio europeo en principio (al reconocer importantes vínculos poscoloniales llenos de pasivos ambientales) y con ello auspiciar un nuevo modelo de sostenibilidad. Producción más limpia, disminución radical de las emisiones de $\mathrm{CO}_{2}$, restauración masiva de las comunidades biológicas y la funcionalidad ecosistémica silvestre, recuperación de los servicios ecosistémicos, promoción de cambios de patrones de comportamiento y consumo: un gran despliegue de alternativas que ya el mundo entero venía predicando hace algunos años para moverse rápidamente fuera de la zona de peligro de la insostenibilidad y el riesgo de colapso, pero difícil de concretar ante la inercia de los procesos del desarrollo convencional, diseñado para sobreponernos rápidamente a una guerra, no para transitar cuidadosamente a un escenario preventivo de muchas guerras...

Lo cierto es que el mundo entero reflexiona acerca del significado de la sostenibilidad pospandemia, pues ha debido recurrir a todas las estrategias que estaban incubándose o reposaban en la vitrina del "rómpase en caso de emergencia", solo que esta se había construido en el más distante de los sótanos, lejos del alcance... de los adultos. Porque las nuevas generaciones están saliendo a la calle a reclamar su derecho al futuro, y no solo un futuro de opciones de consumo, sino también un futuro donde la inequidad, construida a partir de una distribución extremadamente desigual de los costos ambientales del bienestar, ya no sea la peor amenaza a la convivencia.

Innovación tecnológica, pero no para incrementar el universo de desechos y la contaminación del mundo, sino para restituir la salud y el goce; artes y ciencia para diseñar un mundo compartido sin la absurda distorsión de la eficiencia del corto plazo, inhibidora de la sostenibilidad profunda; cambios institucionales, no para

1 Rectora, Universidad EAN, Bogotá. Correo: rectoríadean.edu.co 
instaurar regímenes oportunistas, sino verdaderos espacios de concertación democrática. A todo ello, le llamamos el espacio de las transformaciones socioecológicas del territorio, una propuesta basada en la certeza de que muchos mundos son posibles, aunque probablemente no se parezcan en nada a los que imaginamos, porque la incertidumbre propia de la dinámica de los sistemas complejos hace que las sorpresas sean más importantes que las determinaciones y las profecías. Por eso mismo, hay que tener motivos para la esperanza... 